\title{
Estímulos fiscales en destinos \\ de sol y playa: una propuesta \\ para Quintana Roo
}

DOI: 10.22403/UQROOMX/TYP05/14

חוח

Sergio Lagunas Puls*

\section{Resumen}

El presente trabajo analiza los estímulos fiscales de los estados de Baja California Sur (Los Cabos) y Sinaloa (Mazatlán), destinos de sol y playa, para identificar aquellos estímulos que pudieran incluirse en Quintana Roo. El texto inicia con una introducción respecto al turismo y las inversiones, posteriormente muestra de forma gráfica el flujo en el desarrollo de la investigación y concluye con una propuesta para incluir criterios referentes a los estímulos fiscales que le permitan al estado y a los municipios de Quintana Roo ofrecer competitividad ante los inversionistas del sector turismo y sectores afines. Tal propuesta podría significar una medida de fomento a la inversión que compense la nueva reforma fiscal para 2008.

Palabras | Quintana Roo, destinos turísticos, estímulos fiscales.

CLAVE 


\section{Introducción}

Los gobiernos, por su responsabilidad de llevar a cabo obras de carácter social, se ven obligados a diversificar sus fuentes tributarias para recaudar fondos que las puedan sustentar;' en este sentido, las actividades económicas, el turismo entre ellas, constituyen uno de los factores que condicionan el desarrollo, favorable o desfavorable, de la captación tributaria. Se pueden distinguir dos tendencias en materia fiscal: una de tipo eminentemente restrictivo y la otra de carácter promocional o estimulante.

Medidas fiscales que afectan la inversión en los servicios turísticos y su operación

La finalidad principal de estas medidas debería ser el incremento de la inversión, para que se instauren y amplíen los servicios. Estos estímulos se conceden en mayor grado en aquellos países en los cuales el turismo representa uno de los renglones más importantes de la economía y, por consiguiente, del desarrollo. Algunas disposiciones de estímulo fiscal son la exención de impuestos a determinado plazo, las zonas de desarrollo turístico, franquicias por la importación de equipo indispensable para la prestación de servicios y otras regulaciones análogas.

\section{Impacto económico}

En nuestro país, el turismo ha sido un detonador de la actividad económica. Por ejemplo, hace 30 años no se había fundado Cancún y hoy tiene entre 500000 y 600000 habitantes, que sumados a los de la Riviera Maya alcanzan los 800000 . Cancún ocupa el cuarto lugar de la República en producto interno bruto (PIB) per cápita, y el segundo en la escala nacional.

Baja California Sur era un territorio despoblado y su única ciudad importante era La Paz. La riqueza que ha propiciado el turismo ha cambiado sustancialmente las condiciones de vida de su población y ha influido a otras regiones del país que estaban en las mismas circunstancias.

'El presente trabajo es parte de una investigación más amplia que se encuentra en evaluación por parte del Consejo Quintanarroense de Ciencia y Tecnología en el marco de los Premios Estatales de Ciencia, Tecnología y Reconocimiento a la Innovación 2007, en la cual se abordan, entre otros temas, los cálculos y comparaciones del costo fiscal y el beneficio del ingreso público. 
Además de suponer una relevante contribución directa a las economías internacionales, el turismo y sus viajes producen un fuerte impacto económico en diversos sectores industriales de bienes de equipo (por ejemplo, aviación), construcción (hoteles, entre otros) y servicios (como la distribución), lo cual queda probado mediante la metodología de la Organización Mundial del Turismo (OMT, 2002).

Ante la necesidad de hacer más atractivo y competitivo a Quintana Roo para el desarrollo de proyectos de inversión turística, este ensayo compara estímulos y legislaciones de fomento económico y fiscal de otros sitios con destinos turísticos de sol y playa como Los Cabos, en Baja California Sur, y Mazatlán, en Sinaloa. La finalidad no es solamente comparar sino identificar aquellos estímulos susceptibles de ser adoptados por el estado y atractivos para futuros inversionistas; y plasmar, así, una propuesta para Quintana Roo.

\section{Metodología}

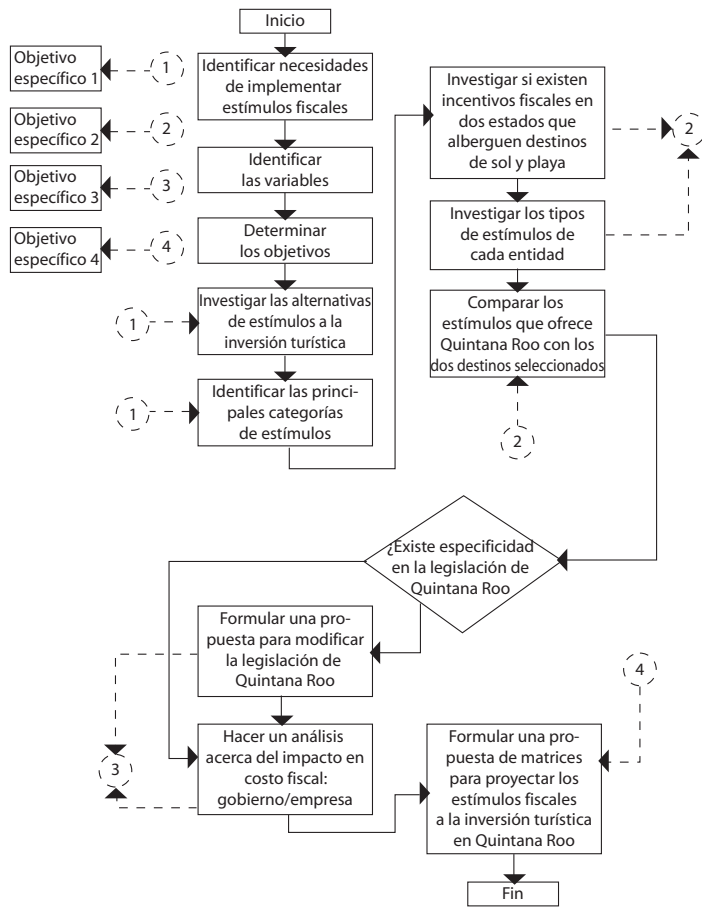




\section{Algunos resultados}

Incentivos fiscales en Baja California Sur y Sinaloa

La legislación de Baja California Sur y Sinaloa favorece la inversión mediante estímulos fiscales.Dan acceso a empresas de reciente creación o a nuevos proyectos de empresas ya establecidas, siempre y cuando cumplan con cada ordenamiento legal. Los estímulos son otorgados en función del grupo o sector al que pertenece el solicitante: si es de la industria de la transformación o si produce bienes de capital; $y$, en el caso de Sinaloa, se privilegia a las empresas relacionadas directamente con el turismo. En ambos estados se incluye un incentivo de tipo administrativo denominado Ventanilla Única, que tiene las siguientes atribuciones:

I. Agilizar, facilitar y gestionar trámites para la obtención de licencias y permisos para el establecimiento, la ampliación, la reubicación y la operación de actividades empresariales

2. Simplificar la regulación jurídico-administrativa de empresas, establecimientos y prestadores de servicios

3. Recibir propuestas y sugerencias del público para hacer más eficientes los trámites y procedimientos; canalizar dichas propuestas al Comité

4. En general, proveer orientación, agilizar trámites y dar seguimiento a todo asunto vinculado con el establecimiento y la operación de actividades empresariales

En las entidades analizadas destaca la existencia de un marco jurídico representado por leyes de fomento económico creadas en 1996: la Ley de Fomento a la Inversión para el Desarrollo Económico del Estado de Sinaloa y la Ley de Fomento Económico del Estado de Baja California Sur.

Los dos estados tienen programas de estímulos bien definidos dirigidos tanto a empresas ya existentes como a las de nueva creación, es decir, su aplicación está dirigida a proyectos que cumplan con los requisitos establecidos.

Ordenamientos legales y estímulos que ofrecen

Baja California Sur y Sinaloa

Una vez examinadas y cotejadas las leyes de fomento y los estímulos fiscales en ellas contemplados, se concluye que: 
I.Ambas leyes de fomento son de reciente promulgación

2. Está bien definida su estructura en cuanto a procedimientos, limitaciones, comités o comisiones encargados de dictaminar las solicitudes, etcétera

3. Los estímulos fiscales que se ofrecen son claros y precisos, aun cuando se observa que en la redacción existen incongruencias gramaticales

4. Es importante destacar que la legislación del estado de Sinaloa menciona concretamente que quien invierta en infraestructura turística es sujeto de los estímulos fiscales, mientras que el estado de Baja California Sur es menos preciso e incluye a la industria turística dentro del concepto de "Empresas que no someten su producción a un proceso de transformación", es decir, cualquier industria no fabril

5. En lo que respecta a las sanciones, la legislación en Sinaloa presenta mayor amplitud en su aplicación, o sea, es menos discrecional y más específica si se le compara con la de Baja California Sur

En esta investigación encontramos que la legislación del estado de Sinaloa es más precisa, mucho más completa y detallada en desarrollo capitular y contenido de artículos (consta de siete títulos y II 2 artículos). La legislación en Baja California Sur está formada por nueve capítulos y 48 artículos.

Impuestos, derechos y aprovechamientos que afectan

a la inversión en Sinaloa y Baja California Sur

Al cotejar los conceptos que se incluyen en ambos estados para ser sujetos de estímulos fiscales, se infiere lo siguiente:

I. Cualquier entidad que ofrezca un estímulo fiscal cuya base de pago esté conformada por el valor del propio bien inmueble (que en el caso de la hotelería es de suma importancia) será mucho más atractiva a la inversión, destacando Baja California Sur en cuanto al impuesto predial, pues independientemente de que ambos estados otorgan el estímulo, esta entidad es más cara respecto a Sinaloa

2. El impuesto sobre la adquisición de bienes inmuebles, muy relacionado con el inicio de un proyecto turístico, también es atractivo para el inversionista, y para cualquier entidad que lo ofrezca representará un valor agregado a la posible inversión turística 
3. El estímulo vinculado con las licencias de construcción es por demás interesante, pues representa un costo definitivo e inapelable al comenzar cualquier proyecto de construcción

4. Una vez iniciado el proyecto o empresa turística de reciente creación, el impuesto a las nóminas es muy atractivo para el inversionista, y además impulsa el empleo

5. Los que menos representan, sin olvidarse de sus correspondientes repercusiones, son aquellos estímulos referentes al pago de derechos al Registro Público

6. Existe un claro efecto y representatividad de la inversión extranjera en cuanto a hotelería y conceptos relacionados con ella en el período 1999-2005, cuando se pusieron en marcha los estímulos fiscales en ambos estados

\section{Conclusiones}

Baja California Sur y Sinaloa, estados con destinos de sol y playa -Los Cabos y Mazatlán, respectivamente-, cuentan con estímulos fiscales orientados a incentivar la inversión no sólo de tipo turístico sino para otros sectores.

En ambos casos, los estímulos fiscales, su identificación y directrices están bien establecidos mediante leyes de fomento económico que detallan los tipos de estímulos, los requisitos, las sanciones, etcétera.

Contar con un impulso de esta naturaleza, establecido en una ley y no producto de la discrecionalidad, motiva al inversionista en su decisión y brinda orden y organización a los gobiernos estatal y local. Las experiencias de Sinaloa y Baja California Sur constituyen dos ejemplos concretos y con resultados positivos.

Con este precedente, es muy importante que la Ley de Desarrollo Económico de Quintana Roo ofrezca transparencia y claridad en el acceso a los estímulos que fomentan la inversión turística y no turística. Esto lleva a proponer un proyecto que promueva una iniciativa para adicionar a la Ley de Desarrollo Económico los artículos necesarios para establecer estímulos fiscales que le permitan al estado y a sus municipios ofrecer un destinto competitivo a la inversión turística, y que contribuya, entre otros aspectos, a generar empleos, un mayor 
consumo de servicios indirectos, modernidad y una mejora en la urbanización general del estado, $y$, sobre todo, a asegurar un sólido y competitivo futuro para la entidad en cuanto a la inversión turística.

En esta propuesta de iniciativa desempeñan un papel muy importante los municipios de Quintana Roo, puesto que son los únicos facultados por la Constitución para fijar los lineamientos para cobrar el impuesto predial: conforme al artículo II 5 de la Constitución, en su fracción IV, algunas fuentes de ingresos, como el cobro del impuesto predial, están reservadas exclusivamente a los municipios. Es esencial que en esta función que cumplen los municipios se considere un criterio para estimar el valor base de impuesto dirigido a atraer inversiones.

Con el fin de apoyar lo anterior, se hace referencia a las desigualdades intencionadas, ${ }^{2}$ las cuales surgen cuando las autoridades reducen a propósito la estimación de la base para algunos contribuyentes. Esta política puede obedecer al interés de inducir a las empresas a establecerse en la jurisdicción atendiendo a los otros impuestos que originan y a que abren fuentes de trabajo y, por tanto, incrementan el valor de la propiedad y el ingreso local.

También la Constitución señala que los ayuntamientos tienen la facultad de proponer tanto las tablas de valores unitarios del suelo que hayan de servir de base para el cobro del impuesto predial, como las cuotas o tarifas que deberán aplicarse sobre esas tablas para el cálculo final de la cantidad a pagar por los contribuyentes. Además, se menciona que a las legislaturas estatales les compete tomar la decisión final sobre estos puntos cuando aprueban las leyes de ingresos de los municipios.

De hecho, no debiera preocupar a los municipios de Quintana Roo la puesta en marcha de estímulos fiscales explícitos y precisos, ya que ello les permitirá situarse en una posición competitiva con municipios de otros estados; la verdadera importancia radica en mejorar su sistema tributario local, para lo cual es básico que logre un sistema de valuación técnica efectivo, ya que de él parte la correcta administración tanto del impuesto predial como del impuesto sobre adquisición de bienes inmuebles.

Quintana Roo y sus municipios deben considerar que por difíciles que sean los problemas técnicos y administrativos que plantea la estructura de estímulos junio].

${ }^{2}$ Suprema Corte de Justicia de la Nación, disponible en <http://www.scjn.gob.mx> [2006, 
Estímulos fiscales en

destinos de sol y playa

fiscales, no son insuperables pero sí pueden serlo aquellos conflictos políticos que suscita. Un antecedente de ello aconteció en el estado de Jalisco, donde nuestro máximo tribunal intervino respecto a la forma de cobro del impuesto predial en el municipio de Guadalajara y su modificación por parte de la legislatura estatal.

La Suprema Corte de Justicia de la Nación (scjN) determinó que esta facultad de las legislaturas está limitada. En opinión de los ministros de la scjN, si las legislaturas estatales modifican las propuestas que les hacen los ayuntamientos sobre la forma en que cobrarán el impuesto predial es necesario que, al momento de aprobar las leyes de ingresos municipales, justifiquen su determinación con argumentos razonables y objetivos.

La resolución de los congresos locales no puede ser arbitraria, porque se corre el riesgo de que a raíz de una decisión política un ayuntamiento vea mermados los recursos económicos que obtiene por concepto de cobro del predial.

De manera unánime, los II ministros de la Suprema Corte de Justicia le concedieron la razón al municipio de Guadalajara, ya que el Congreso de su entidad modificó su propuesta de cobro del predial sin argumentar ni justificar su decisión.

CUADRO I. INVERSIÓN EXTRANJERA DIRECTA CAPTADA POR ACTIVIDADES TURÍSTICAS

\begin{tabular}{|c|c|c|c|}
\hline Estado & $\begin{array}{c}\text { Principales } \\
\text { destinos de sol y } \\
\text { playa }\end{array}$ & $\begin{array}{l}\text { Inversión extranjera } \\
\text { directa (IED) } \\
\text { (millones de } \\
\text { dólares) }\end{array}$ & $\begin{array}{l}\text { Participación en el } \\
\text { total de inversión } \\
\text { extranjera directa }\end{array}$ \\
\hline $\begin{array}{l}\text { Baja California } \\
\text { Sur }\end{array}$ & Los Cabos & 879.3 & $\begin{array}{l}\text { Equivale a } 0.8 \% \text { de la IED } \\
\text { materializada en ese } \\
\text { lapso ( } 109275.7 \\
\text { millones de dólares) }\end{array}$ \\
\hline Quintana Roo & $\begin{array}{l}\text { Cancún, Riviera Maya } \\
\text { (Playa del Carmen, } \\
\text { Puerto Aventuras, } \\
\text { Tulum) }\end{array}$ & 463.5 & $\begin{array}{l}\text { Equivale a } 0.4 \% \text { de la IED } \\
\text { materializada en ese } \\
\text { lapso ( } 109275.7 \\
\text { millones de dólares) }\end{array}$ \\
\hline Sinaloa & Mazatlán & 163.3 & $\begin{array}{l}\text { Equivale a } 0.1 \% \text { de la IED } \\
\text { materializada en ese } \\
\text { lapso ( } 109275.7 \\
\text { millones de dólares) }\end{array}$ \\
\hline
\end{tabular}


Por otra parte, si bien la inversión extranjera directa captada por actividades relacionadas con el turismo es mayor en proporción para Quintana Roo que para los dos estados comparados, en el periodo de enero de 1999 a junio de 2005 la inversión extranjera directa general fue atraída en mayor medida por Baja California Sur (Secretaría de Economía, 2005a) que representa casi el doble de la inversión extranjera directa captada en ese mismo lapso en Quintana Roo.

La información contenida en el cuadro I muestra que Quintana Roo ha sido desplazado por Baja California Sur en cuanto a inversión extranjera directa y esto hace evidente que de no clarificar y ofrecer estímulos a la inversión esta cifra podría incrementarse en beneficio de otros estados donde exista mayor certidumbre fiscal. En la actualidad, cuando ambos destinos enfrentan condiciones similares de tendencias mundiales en la demanda turística y concentración en el mercado norteamericano, además de otros rasgos que los identifican, la disposición de un esquema de estímulos fiscales integrado puede constituir la diferencia.

Los municipios y el gobierno del estado de Quintana Roo tendrán que compartir la propuesta de iniciativa que lleve a delimitar y clarificar los estímulos fiscales mediante la creación de un consejo para fomentar el desarrollo económico, integrado por representantes de los gobiernos estatal y municipal.

Respecto a la mecánica para la solicitud, trámite y resolución correspondiente a los estímulos fiscales, se deberán sugerir como anexos las propuestas de solicitud, el diagrama de flujo y su matriz de análisis por tareas, con el fin de proyectar de forma transparente y exacta los pasos para el otorgamiento de los estímulos que han de ayudar a mantener al estado de Quintana Roo como uno de los principales destinos no sólo para visitantes sino para nuevas inversiones turísticas.

\section{FUENTES CONSULTADAS}

Getino, Octavio (2002). Turismo. Entre el ocio y el negocio. Buenos Aires: La Crujía Ediciones/Ciccus.

IMCP (2003). “Industria del Turismo: Entrevista al director general de Fonatur”, Revista Contaduría Pública, Instituto Mexicano de Contadores Públicos, junio. 
OMT (200I) Tendencias de los mercados turísticos: panorama mundial y actualidad del turismo. Madrid: Organización Mundial del Turismo. (2002). La fiscalidad del turismo: hacia un justo equilibrio. Madrid: Organización Mundial del Turismo.

Secretaría de Economía (2005a). Informe de inversión extranjera en el estado de Baja California Sur.Subsecretaría de Normatividad, Inversión Extranjera y Prácticas Comerciales Internacionales.

(2005b) Informe de inversión extranjera en el estado de Sinaloa. Subsecretaría de Normatividad, Inversión Extranjera y Prácticas Comerciales Internacionales.

(2005c) Informe de inversión extranjera en el estado de Quintana Roo. Subsecretaría de Normatividad, Inversión Extranjera y Prácticas Comerciales Internacionales. 